\title{
Hormone replacement therapy in chronic active hepatitis; a case report
}

\author{
D Clements, J Rhodes
}

\begin{abstract}
There is an increased incidence of osteoporosis in patients with chronic liver disease. Because patients with chronic active hepatitis (CAH) usually require corticosteroids for their liver disease prevention and treatment of bone loss presents a difficult problem. This case report describes a 41 year old female patient with CAH who had a high rate of bone loss. After an early menopause with noticeable menopausal symptoms, she was given transdermal oestrogen replacement therapy. The menopausal symptoms resolved completely, and there was no deterioration in her liver function tests or corticosteroid requirement. In addition, follow up quantitative bone mineral measurements over two years have shown improvement. This case shows the value of measurements of bone density, and oestrogen replacement therapy in CAH, even in the presence of continued corticosteroids. (Gut 1993; 34: 1639-1640)
\end{abstract}

There is an increased incidence of osteoporosis in patients with chronic liver disease. Cross sectional studies of patients with chronic active hepatitis $(\mathrm{CAH})$ have shown an increased prevalence of reduced bone density and osteoporotic fractures. ${ }^{1-3}$ Although a longitudinal study of women with $\mathrm{CAH}$ has shown that most patients do not lose significant amounts of trabecular bone, some younger patients have high rates of loss. ${ }^{4}$

We present one of our patients who in a previous study was found to have high rates of bone loss. She subsequently had a premature menopause, and was given hormone replacement therapy (HRT) to control menopausal symptoms and bone loss.

\section{Case report}

The patient was well until she was 26 when she presented with acute nausea, anorexia, and severe jaundice. There was no previous history of note and virological investigations were negative for hepatitis A and B. Liver function tests showed a considerable hepatitis with serum aspartate transaminase activities of $1600 \mathrm{IU} / \mathrm{l}$ (normal 5-33), albumin 39 g/l (normal 35-48), total protein $79 \mathrm{~g} / 1$ (normal 60-80), alkaline phosphatase 75 IU/l (normal 10-40), and bilirubin of $825 \mu \mathrm{mol} / \mathrm{l}$ (normal <17). Antinuclear antibodies were positive and liver biopsy confirmed a diagnosis of chronic active hepatitis with severe portal tract inflammation, and piecemeal necrosis.

She was treated with azathioprine $(100 \mathrm{mg}$ ) and prednisolone, initially $20 \mathrm{mg}$ a day. Her jaundice resolved completely and follow up liver biopsy showed a reduction in the inflammation. Over the next eight years she was maintained with azathioprine (100 mg/day) and prednisolone (average dose $7.5 \mathrm{mg}$ ). Four attempts were made to withdraw corticosteroids but on each occasion her liver function deteriorated with rises in aspartate transaminase, which resolved when prednisolone was recommenced.

Nine years after presentation (aged 35) she had normal liver function tests while taking $100 \mathrm{mg}$ azathioprine and $5 \mathrm{mg}$ prednisolone daily. Her radial and spinal bone density were measured by single photon absorptiometry and quantitative computed tomography as part of the cross sectional study. ${ }^{1}$ Her initial radial bone mineral content related to bone width $(\mathrm{BMC} / \mathrm{BW})$ was $0.72 \mathrm{~g} / \mathrm{cm}^{2}(Z$ score $=0.00)$ and spinal bone mineral density (BMD) was $168 \mathrm{~g} / \mathrm{l} \quad(\mathrm{Z}$ score $=-0.91) .^{5}$

She remained well while receiving the same treatment apart from developing irregular periods. Her bone mineral density was again measured 3.3 years later as part of a follow up study in patients with CAH. ${ }^{4}$ Her radial $\mathrm{BMC} /$ BW was $0.67 \mathrm{~g} / \mathrm{cm}^{2}(Z$ score $=-1.00)$ and spinal BMD $155 \mathrm{~g} / 1(\mathrm{Z}$ score $=-1 \cdot 19)$; these values are equivalent to an annual reduction at both sites of $-2 \cdot 8 \% /$ year.

Shortly after the second measurement, her periods stopped and she developed menopausal symptoms of night sweats, hot flushes, and vaginal dryness. Her postmenopausal state was confirmed by a low plasma oestradiol and raised gonadotrophins.

Because of her marked symptoms, premature menopause, requirement for corticosteroids and previously reported high rates of bone loss she was given hormone replacement therapy (HRT). She was given transdermal oestrogen $(50 \mu \mathrm{g}$ oestradiol patch) with cyclical oral progestogen (1 $\mathrm{mg}$ norethisterone) in the formulation 'Estrapak 50' (Ciba-Geigy).

Her menopausal symptoms resolved completely and she had regular periods. Liver function tests remained normal with the same dose of prednisolone over the next two years. Follow up bone density measurements showed subsequent improvement in radial $\mathrm{BMC} / \mathrm{BW}$ to $0.78 \mathrm{~g} / \mathrm{cm}^{2}$ $(Z$ score $=+1 \cdot 40)$ and spinal $B M D$ to $169 \mathrm{~g} / 1$ (Z score $=-0.56$ ) (Figure).

\section{Discussion}

This is the first report of treatment with hormone replacement therapy (HRT) in a patient with $\mathrm{CAH}$ that follows the effect on bone density and liver function; oestrogen replacement was effective in reversing the fall in bone density despite the chronic liver disease and continued treatment with corticosteroid.

Corticosteroids are clearly beneficial in $\mathrm{CAH}$

\author{
J Rhodes \\ Dr D Clements, c/o Professor \\ J Rhodes secretary, University \\ Park, Cardiff CF4 4XW. \\ Accepted for publication \\ 26 July 1993 \\ Department of \\ University Hospital of \\ Wales, Cardif
}




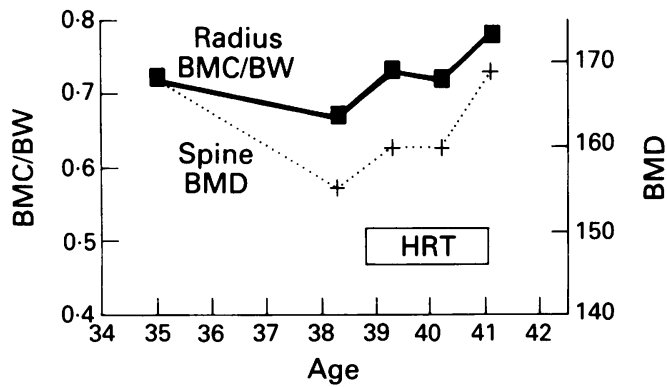

Changes in spinal bone mineral density $(B M D ; g / l)$ and radial bone mineral content $\left(B M C / B W ; \mathrm{g} / \mathrm{cm}^{2}\right)$ in a woman with chronic active hepatitis who was treated with transdermal oestrogen replacement therapy $(H R T)$

and improve the prognosis. ${ }^{6-9}$ Their use, however, is associated with significant morbidity, in particular osteoporosis and spinal fractures. ${ }^{6-10}$

Although a follow up study of $\mathrm{CAH}$ showed that most women do not lose large amounts of bone, the patient we report had suffered high rates of bone loss despite small doses of corticosteroid. ${ }^{4}$ Her premature menopause with oestrogen deficiency was a factor which contributed to the bone loss.

In normal women, HRT has been shown to reduce bone loss and fractures; as in our patient, most studies have shown a small improvement in bone density with treatment. Patients with inflammatory bowel disease and rheumatoid arthritis have also shown similar improvements. ${ }^{5-11}$ Another recent study has shown that HRT is effective in reducing bone loss in most patients receiving concurrent corticosteroids. ${ }^{12}$ There is therefore evidence from several sources that HRT can improve bone density in a variety of diseases.

Although HRT is usually avoided in most patients with chronic liver disease, HRT should be considered for these patients who are particularly at risk of bone loss and osteoporotic fracture, if the effect on both the liver function and bone density are carefully followed up. As well as improvement in bone density, our patient was pleased with the resolution of her symptoms, which had not responded to other treatments. A recent report of HRT in 16 women with primary biliary cirrhosis showed a reduction in bone loss compared with 91 untreated patients and there was no associated deterioration in liver function. ${ }^{13}$ There is considerable reservation about using HRT in chronic liver disease associated with cholestasis because of the fear that liver function may deteriorate. These findings give some encouragement for a trial of oestrogens in patients at risk of developing osteoporosis while taking corticosteroids for their liver disease.

There have been no comparative studies of transdermal and oral oestrogens in the preven- tion and treatment of osteoporosis, and most of the data on safety and efficacy of HRT are based on oral therapy. Oral therapy therefore remains first line therapy. In patients with chronic liver disease, however, it may be an advantage to prevent first pass hepatic metabolism by transdermal administration.

Because of the individual variations in bone mass and rates of loss in patients with $\mathrm{CAH}$ there is probably a place for regular measurements of bone density. The radiation exposure entailed is low and repeat measurements make it possible to estimate the rates of bone loss; such information may help in the management of individual patients. One of the major complications of corticosteroid treatment for CAH can now be monitored and appropriate changes made in treatment. In addition, bone loss and osteoporotic fracture have been a major complication after liver transplantation; it is important to maintain bone mineral density in patients who may subsequently require a transplant. ${ }^{14}$

1 Rose J, Compston JE, Crawley EO, Evans WD, Evans C Smith PM. Osteoporosis associated with chronic liver disease. Eur f Gastroenterol Hepatol 1991; 3: 63-9.

2 Diamond T, Stiel D, Lunzer M, Wilkinson M, Roche J, Rosen $\mathrm{S}$. Osteoporosis and skeletal fractures in chronic liver disease. Gut 1990; 31: 82-7.

3 Stellon AJ, Davies A, Compston J, Williams R. Bone loss in autoimmune chronic active hepatitis on maintenance corticosteroid therapy. Gastroenterology 1985; 89: 1078-83.

4 Low dose corticosteroids in chronic active hepatitis do no adversely affect spinal bone. Clements $\mathrm{D}$, Compston JE Rhodes J, Evans WD, Smith PM. Eur $\mathcal{f}$ Gastroenterol Hepatol 1993; 5: 543-7.

5 Clements D, Compston JE, Evans WD, Rhodes J. Hormone replacement therapy prevents bone loss in patients with inflammatory bowel disease. Gut 1993; 34: 1543-6.

6 Cook GC, Mulligan R, Sherlock S. Controlled prospective tria of corticosteroid therapy in active chronic hepatitis. $O F \mathrm{Med}$ 1971; 158: 159-85.

7 Soloway RD, Summerskill WHJ, Baggenstoss AH, Geall MG Gitnick GL, Elveback LR, et al. Clinical, biochemical, and histological remission of severe chronic active liver disease: a controlled study of treatments and early prognosis. Gastroenterology 1972; 63: 820-33.

8 Murray-Lyon IM, Stern RB, Williams R. Controlled trial of Murray-Lyon IM, Stern RB, Williams $R$. Controlled trial of
prednisone and azathioprine in active chronic hepatitis. Lancet 1973, i: $735-7$.

9 Summerskill WHJ, Korman MG, Ammon HV, Baggenstos AH. Prednisone for chronic active liver disease: dose titration, standard dose, and combination azathioprine compared. Gut 1975; 16: 876-83.

10 Kirk AP, Jain S, Pocock S, Thomas HC, Sherlock S. Late results of the Royal Free Hospital prospective controlled trial of prednisolone therapy in hepatits $B$ surface antigen negative chronic active hepatitis. Gut 1980; 21: 78-83.

11 Brink HR, Lems WF, Everdingen AA, Bijlsma JWJ. Adjuvant oestrogen treatment increases bone mineral Adjuvant oestrogen treatment increases bone mineral density in postmenopausal women with

12 Lukert BP, Johnson BE, Robinson RG. Estrogen and progesterone replacement therapy reduces glucorticoid-induced

13 Crippin JS, Jorgensen RA, Dickson ER, Lindor KD. Hepatic osteodystrophy in primary biliary cirrhosis: the effects of estrogen administration. Gastroenterology 1992; 102: A796.

14 McDonald JA, Dunstan CR, Dilworth P, Sherbon K, Ross Shiel AG, Evans RA, et al. Bone loss after liver transplantation. Hepatology 1991; 14: 613-9.

15 Porayko MK, Wiesner RH, Hay JE, Krom RAF, Dickson ER Beaver S, et al. Bone disease in liver transplant recipients: incidence, timing, and risk factors. Trans Proc 1991; 23: $1462-5$. 